\title{
Influence of Synbiotics on Selected Oxidative Stress Parameters
}

\author{
Paulina Kleniewska and Rafał Pawliczak \\ Department of Immunopathology, Faculty of Biomedical Sciences and Postgraduate Training, Medical University of Lodz, \\ 7/9 Zeligowskiego St, 90-752 Lodz, Poland \\ Correspondence should be addressed to Rafał Pawliczak; rafal.pawliczak@csk.umed.lodz.pl
}

Received 13 October 2016; Revised 21 December 2016; Accepted 15 January 2017; Published 13 February 2017

Academic Editor: Ilaria Peluso

Copyright (C) 2017 Paulina Kleniewska and Rafał Pawliczak. This is an open access article distributed under the Creative Commons Attribution License, which permits unrestricted use, distribution, and reproduction in any medium, provided the original work is properly cited.

\begin{abstract}
The aim of the present study was to assess synbiotic (Lactobacillus casei + inulin) influence on oxidative stress parameters such as concentrations of malondialdehyde (MDA), hydrogen peroxide $\left(\mathrm{H}_{2} \mathrm{O}_{2}\right)$, glutathione, and free sulfhydryl groups content. Experiments were carried out on healthy volunteers $(n=32)$. The subjects were divided into women group $(n=16)$ and men group $(n=16)$ and randomly assigned to synbiotic and control groups. Blood samples were collected before synbiotic supplementation and after $7 \mathrm{wks}$, at the end of the study. The administration of synbiotic resulted in a significant decrease in $\mathrm{MDA}(p<0.01), \mathrm{H}_{2} \mathrm{O}_{2}$ $(p<0.01)$, and GSSG concentrations $(p<0.05)$ as compared with the control groups and significant increase in the concentrations of GSHt $(p<0.001)$, GSH $(p<0.01)$, and -SH group content $(p<0.05)$ versus control. Synbiotics containing $L$. casei plus inulin may have positive influence on selected oxidative stress markers.
\end{abstract}

\section{Introduction}

Reactive oxygen species (ROS) are defined as chemical molecules generated by a partial reduction of molecular oxygen [1]. ROS can be divided into oxygen-centered radicals, for example, superoxide anion and oxygen-centered nonradicals such as hydrogen peroxide [2-4].

ROS that are generated in many ways during different endogenous and exogenous processes have many physiological functions but they are also involved in pathological conditions $[5,6]$. Fortunately, a human body has developed a number of nonenzymatic defense mechanisms against harmful effects of ROS. There are hydrophilic and hydrophobic antioxidants. The first group includes glutathione or ascorbate (vitamin $\mathrm{C}$ ). They aim at protecting the aquatic environment of the cell. Hydrophobic antioxidants include carotenoids, vitamin and provitamin $\mathrm{D}_{3}$, and tocopherols. Their goal is to remove ROS from the area of cell membranes and inhibit lipid peroxidation $[7,8]$.

Synbiotics are products which contain both probiotics and prebiotics (nondigestible food ingredients that beneficially affect the host by selectively stimulating the growth or/and activity of one/or a limited number of bacteria in the colon) [9].
There are pieces of evidence that confirm the antioxidative properties of probiotics/synbiotics. Strains that are considered to be the most important probiotics in this area are Lactobacillus and Bifidobacterium. A decrease in the number of oxidative stress markers after probiotics supplementation in many studies was reported [10, 11]. Suo et al. [12] showed that after administration of L. fermentum Suo to mice with gastric injuries MDA concentrations were significantly reduced when compared to the mice which were not supplemented with this probiotic. Similarly, Tian et al. [13] evaluated the influence of L. rhamnosus CCFM1107 on alcohol induced-liver injury in the ICR mice. The study revealed that concentrations of plasma MDA were significantly lower after supplementation of these bacteria. Also, Zhang et al. [14] confirmed that male Sprague Dawley rats after application of $L$. casei Zhang demonstrated decreased MDA plasma levels. Other study [15] assessed protective effects of $L$. plantarum CCFM8610 against acute cadmium toxicity in adult male Kunming mice. Uskova and Kravchenko [16] observed that only L. casei spp. (including L. casei 114001) had antioxidant properties which affected the blood plasma, liver, and intestines of Wistar rats and contributed to a decrease in the MDA content in the blood plasma. Al-Sheraji et al. [17] examined the effect of a yoghurt 
supplement containing B. pseudocatenulatum G4/B. longum $B B 536$ on lipid peroxidation in rats fed a cholesterol-enriched diet. Animal groups which were fed this diet, supplemented with B. pseudocatenulatum G4 or B. longum BB536, demonstrated a significantly lower plasma MDA level. Gao et al. [18] observed that FC225 strains of L. plantarum provide antioxidant properties. Authors of another study [19] proved that supplementation of the probiotic decreased MDA levels in the serum of $90 \mathrm{~kg}$ pigs.

The aim of the study was to evaluate selected oxidative stress parameters such as concentration of $\mathrm{MDA}, \mathrm{H}_{2} \mathrm{O}_{2}$, GSHt, GSSG, GSH, and free sulfhydryl (-SH) groups content after administration of synbiotic in human plasma of healthy volunteers.

\section{Materials and Methods}

2.1. Experimental Design. As we described previously [20] the study was carried out in Poland between December 2014 and February 2015 on 32 healthy volunteers (20-35 years old), randomly divided into synbiotic and control groups. Excluding criteria of the experiment were administration of antimicrobial, anti-inflammatory, or nonsteroidal drugs over last three months, gastrointestinal disease, food allergy or acute infections, and administration of yoghurt/vitamins/other products that may influence antioxidant activity of plasma. Also athletes and active and passive smokers were excluded. Blood samples from the forearm veins were collected before synbiotic administration and after 7 wks when the study finished. The protocol of the study was approved by the Ethical Committee of Medical University of Lodz (number $\mathrm{RNN} / 801 / 14 / \mathrm{KB})$.

2.2. Tested Dietary Supplement. A synbiotic (Lactobacillus casei with inulin) was purchased from ICN Polfa Rzeszow SA, Poland. Each capsule contained $4 \times 10^{8} \mathrm{CFU}$ lyophilized Lactobacillus casei and $400 \mathrm{mg}$ of inulin. Subjects were given one capsule of synbiotic per day, at dinner time for 7 weeks [20].

\subsection{Measurement of MDA Concentration in Human Plasma.} To measure MDA concentration, Lipid Peroxidation Assay Kit (Colorimetric/Fluorometric) (Item number ab118970), manufactured by Abcam (Symbios Sp. z o.o. 83-010 Straszyn, ul. Modrzewiowa 37, Poland) was used. This method is based on the reaction of free MDA (present in the sample) with thiobarbituric acid (TBA) to generate a MDA-TBA adduct [21].

2.3.1. Chemicals. Lipid Peroxidation Assay Kit (Item number ab118970) consisted of MDA lysis buffer, phosphotungstic acid solution, BHT (100x), MDA Standard, and TBA solution; one vial of TBA was reconstituted with $7.5 \mathrm{~mL}$ of glacial acetic acid; in the next step $\mathrm{ddH}_{2} \mathrm{O}$ was added to $25 \mathrm{~mL}$.

2.3.2. Sample Preparation. To prepare samples $10 \mu \mathrm{L}$ of plasma with $500 \mu \mathrm{L}$ of $42 \mathrm{mM} \mathrm{H}_{2} \mathrm{SO}_{4}$ was mixed. Then $125 \mu \mathrm{L}$ of phosphotungstic acid was added and mixed. In the next step, the samples were incubated (room temperature, 5 minutes) and centrifuged at 13000 for 3 minutes; then the pellet was collected and resuspended on ice with $100 \mu \mathrm{L}$ of $\mathrm{ddH}_{2} \mathrm{O}$. At the end, $200 \mu \mathrm{L}$ of $\mathrm{ddH}_{2} \mathrm{O}_{2}$ was adjusted to the final volume.

2.3.3. Assay Protocol. After preparation of MDA standard $(0.1 \mathrm{M}-10 \mu \mathrm{L}$ of $4.17 \mathrm{M}$ MDA Standard was diluted in $407 \mu \mathrm{L}$ of $\mathrm{ddH}_{2} \mathrm{O} ; 2 \mathrm{mM}-10 \mu \mathrm{L}$ of $0.1 \mathrm{M}$ MDA Standard was diluted in $490 \mu \mathrm{L}$ of $\mathrm{ddH}_{2} \mathrm{O}$ ) each well on the plate was filled with $600 \mu \mathrm{L}$ of TBA reagent and incubated at $95^{\circ} \mathrm{C}$ for 60 minutes and cooled to room temperature on ice for 10 minutes. Then, $300 \mu \mathrm{L}$ of $\mathrm{n}$-butanol and $100 \mu \mathrm{L}$ of $5 \mathrm{M} \mathrm{NaCl}$ were added to wells. The layers were separated by centrifugation $(3 \mathrm{~min}$ at $16,000 \times \mathrm{g})$. Next step was to transfer the MDA-TBA adduct to a new tube and evaporate the n-butanol. Then, MDA-TBA adduct was dissolved in $200 \mu \mathrm{L}$ of $\mathrm{ddH}_{2} \mathrm{O}$ and placed into the 96-well plate microplate for analysis. Absorbance was read at $532 \mathrm{~nm}$ with plate reader (TECAN Sunrise with software Magellan Standard).

2.4. Measurement of $\mathrm{H}_{2} \mathrm{O}_{2}$ Concentration in Human Plasma. To measure $\mathrm{H}_{2} \mathrm{O}_{2}$ concentration Hydrogen Peroxide Assay Kit (Item number ab102500) manufactured by Abcam (Symbios Sp. z o.o. 83-010 Straszyn, ul. Modrzewiowa 37, Poland) was used. This method is based on the reaction of substrate for hydrogen peroxide with $\mathrm{H}_{2} \mathrm{O}_{2}$ in the presence of horseradish peroxidase to produce product with color [22].

2.4.1. Chemicals. Hydrogen Peroxide Assay Kit (Item number ab102500) consisted of $25 \mathrm{~mL}$ of $\mathrm{H}_{2} \mathrm{O}_{2}$ Assay Buffer and $200 \mu \mathrm{L}$ of OxiRed Probe (in DMSO) $100 \mu \mathrm{L}$ of $0.88 \mathrm{M} \mathrm{H}_{2} \mathrm{O}_{2}$ Standard and HRP dissolved in $220 \mu \mathrm{L}$ Assay Buffer.

2.4.2. Sample Preparation. The plasma was centrifuged at $1000 \times \mathrm{g}$ for 15 minutes at $4^{\circ} \mathrm{C}$; then the pellet was removed and kept on ice and deproteinization was carried out according to the manual.

2.4.3. Assay Procedure. After preparation of $\mathrm{H}_{2} \mathrm{O}_{2}$ Standard wells $\left(10 \mathrm{mM}-10 \mu \mathrm{L}\right.$ of $\mathrm{H}_{2} \mathrm{O}_{2} \quad 0.88 \mathrm{M}$ Standard was diluted in $870 \mu \mathrm{L}$ of $\mathrm{dH}_{2} \mathrm{O} ; 0.1 \mathrm{mM}-10 \mu \mathrm{L}$ of $10 \mathrm{mM} \mathrm{H}_{2} \mathrm{O}_{2}$ Standard was dissolved in $990 \mu \mathrm{L}$ of $\mathrm{dH}_{2} \mathrm{O}$ ) each well on the plate was filled with $50 \mu \mathrm{L}$ of Reaction Mix into each well and incubated at room temperature for $10 \mathrm{~min}$. Absorbance was read at $570 \mathrm{~nm}$.

2.5. Measurement of GSHt, GSSG, and GSH Concentration in Human Plasma. To measure GSHt concentration mixture containing $50 \mu \mathrm{L}$ of the plasma, $700 \mu \mathrm{L}$ of $0.2 \mathrm{mM}$ NADPH, $100 \mu \mathrm{L}$ of $0.6 \mathrm{mM}$ DTNB, and $150 \mu \mathrm{L}$ of $\mathrm{H}_{2} \mathrm{O}$ were prepared. The cuvette was incubated at $+37^{\circ} \mathrm{C}$ for $5 \mathrm{~min}$ and then supplemented with $0.7 \mathrm{U}$ of glutathione reductase (GR). The reaction kinetics was traced for $5 \mathrm{~min}$ by monitoring the increase in absorbance. GSSG content was determined using the same protocol after optimization of $\mathrm{pH}$ to 6-7 with $1 \mathrm{M}$ TEA, and endogenous GSH was determined with 2-vinylpyridine. The GSH concentration was calculated as the difference between GSHt and GSSG. The increments in absorbance at $412 \mathrm{~nm}$ were converted to GSH and GSSG 
TABLE 1: The influence of synbiotic containing Lactobacillus casei and inulin on the concentrations of selected oxidative stress parameters. Data is shown as mean \pm SEM. ${ }^{*} p<0.01,{ }^{* *} p<0.001$, and ${ }^{\#} p<0.05$ versus control group.

\begin{tabular}{|c|c|c|c|c|c|c|c|}
\hline \multirow{2}{*}{ Study groups } & \multicolumn{7}{|c|}{ OS parameters } \\
\hline & $\mathrm{MDA}[\mathrm{nmol} / \mathrm{mL}]$ & $\mathrm{H}_{2} \mathrm{O}_{2}[\mathrm{pmol} / \mu \mathrm{L}]$ & GSHt $[\mu \mathrm{M}]$ & $\mathrm{GSH}[\mu \mathrm{M}]$ & GSSG $[\mu \mathrm{M}]$ & $\mathrm{GSH} / \mathrm{GSSG}[\mu \mathrm{M}]$ & -SH groups $[\mu \mathrm{M}]$ \\
\hline Control “0” & $7.32 \pm 0.10$ & $0.37 \pm 0.01$ & $18.42 \pm 0.77$ & $17.13 \pm 0.85$ & $1.29 \pm 0.23$ & $13.28 \pm 0.90$ & $82.58 \pm 0.61$ \\
\hline Control "7 wks" & $7.94 \pm 0.44$ & $0.45 \pm 0.01$ & $19.09 \pm 0.98$ & $17.21 \pm 1.24$ & $1.88 \pm 0.07$ & $9.15 \pm 0.76^{\#}$ & $84.06 \pm 0.82$ \\
\hline Synbiotics “0” & $9.44 \pm 0.01$ & $0.49 \pm 0.01$ & $19.93 \pm 0.89$ & $18.78 \pm 0.89$ & $1.15 \pm 0.15$ & $16.33 \pm 1.98$ & $76.98 \pm 0.75$ \\
\hline Synbiotics "7 wks" & $8.68 \pm 0.01^{*}$ & $0.38 \pm 0.02^{*}$ & $25.21 \pm 0.12^{* *}$ & $24.43 \pm 0.97^{*}$ & $0.78 \pm 0.21^{\#}$ & $31.32 \pm 1.99^{* *}$ & $86.89 \pm 0.68^{\#}$ \\
\hline Female control "0" & $7.03 \pm 0.11$ & $0.36 \pm 0.03$ & $18.36 \pm 0.23$ & $18.13 \pm 0.45$ & $1.37 \pm 0.04$ & $13.23 \pm 0.89$ & $79.43 \pm 0.11$ \\
\hline $\begin{array}{l}\text { Female control } \\
\text { "7 wks" }\end{array}$ & $7.58 \pm 0.12$ & $0.45 \pm 0.02$ & $19.28 \pm 0.10$ & $17.21 \pm 0.11$ & $1.83 \pm 0.03$ & $9.40 \pm 0.67$ & $80.93 \pm 0.13$ \\
\hline $\begin{array}{l}\text { Female synbiotic } \\
\text { "0" }\end{array}$ & $9.24 \pm 0.22$ & $0.49 \pm 0.01$ & $18.99 \pm 0.21$ & $19.78 \pm 0.24$ & $1.17 \pm 0.01$ & $16.08 \pm 0.87$ & $77.04 \pm 1.23$ \\
\hline $\begin{array}{l}\text { Female synbiotic } \\
\text { "7 wks" }\end{array}$ & $8.20 \pm 0.10^{*}$ & $0.36 \pm 0.01^{* *}$ & $26.68 \pm 0.45^{* *}$ & $28.61 \pm 0.19^{* *}$ & $0.81 \pm 0.06^{* *}$ & $35.32 \pm 0.69$ & $90.99 \pm 0.19^{* *}$ \\
\hline Male control "0" & $7.60 \pm 0.40$ & $0.38 \pm 0.02$ & $18.46 \pm 0.40$ & $16.13 \pm 0.42$ & $1.23 \pm 0.10$ & $14.09 \pm 0.41$ & $85.73 \pm 0.41$ \\
\hline $\begin{array}{l}\text { Male control } \\
\text { "7 wks" }\end{array}$ & $8.30 \pm 0.20$ & $0.40 \pm 0.01$ & $18.91 \pm 0.20$ & $17.21 \pm 0.20$ & $1.92 \pm 0.09$ & $8.96 \pm 0.90$ & $87.19 \pm 0.20$ \\
\hline Male synbiotic “0” & $9.65 \pm 0.03$ & $0.52 \pm 0.02$ & $20.87 \pm 0.10$ & $18.78 \pm 0.14$ & $1.13 \pm 0.06$ & $16.62 \pm 0.65$ & $76.91 \pm 1.11$ \\
\hline $\begin{array}{l}\text { Male synbiotic } \\
\text { "7 wks" }\end{array}$ & $9.15 \pm 0.10^{\#}$ & $0.44 \pm 0.05$ & $23.74 \pm 0.11^{*}$ & $19.94 \pm 0.10^{\#}$ & $0.75 \pm 0.07^{*}$ & $25.59 \pm 0.14$ & $82.79 \pm 0.17^{*}$ \\
\hline
\end{tabular}

levels using a standard curve (3.2-500 $\mu \mathrm{M}$ of GSH for GSHt and $0.975-60 \mu \mathrm{M}$ of GSSG for GSSG). Obtained results were expressed in $\mu \mathrm{M}$. The redox ratio of each sample was calculated by dividing its reduced glutathione content by its oxidized glutathione content.

2.6. Measurement of Free -SH Groups Concentration. The total sulfhydryl groups content was determined using the Ellman method [23], based on the reaction of $5,5^{\prime}$-dithiobis (2-nitrobenzoic acid) with thiol groups of proteins. To measure $-\mathrm{SH}$ group concentration we prepared a mixture containing $500 \mu \mathrm{L}$ of the plasma, $500 \mu \mathrm{L}$ of $0.3 \mathrm{M} \mathrm{Na}_{2} \mathrm{HPO}_{4}$, and $500 \mu \mathrm{L}$ of $0.04 \%$ Ellman reagent (DTNB). The last component was freshly dissolved in a solution of $10 \%$ sodium citrate. Absorbance was measured at $412 \mathrm{~nm}$ with a spectrophotometer (Perkin-Elmer Lambda 25).

2.7. Statistical Analysis. The data are presented as mean \pm SEM (standard error of the mean) in each group. The statistical analysis was performed by ANOVA followed by a post hoc Duncan's multiple range test. A $p$ value lower than 0.05 was considered significant.

\section{Results}

3.1. Evaluation of $\mathrm{MDA}$ and $\mathrm{H}_{2} \mathrm{O}_{2}$ Concentrations. An insignificant increase in MDA levels was observed in the control group, female-control group, and male-control group. A significant decrease in MDA levels was observed in the synbiotic group $(p<0.01)$, female-synbiotic group $(p<$ 0.01 ), and male-synbiotic group $(p<0.05)$ in comparison to the their control groups (resp.) before experiments (Table 1).

An insignificant increase in the $\mathrm{H}_{2} \mathrm{O}_{2}$ concentration in the control group, female-control group, and male-control group was observed. A significant decrease in $\mathrm{H}_{2} \mathrm{O}_{2}$ concentration was observed in the synbiotic group $(p<0.01)$ and female-synbiotic group $(p<0.001)$ in comparison to the their control groups before experiments (resp.). There was an insignificant decrease in the $\mathrm{H}_{2} \mathrm{O}_{2}$ level in the male-synbiotic group versus control group (Table 1).

3.2. Evaluation of GSHt, GSSG, and GSH Concentrations and -SH Groups Content. Levels of GSHt and GSH in the control group, female-control group, and male-control group were not significantly higher than those of the control group before experiment. Supplementation of synbiotic significantly improved levels of GSHt and GSH in the synbiotic group (resp. $p<0.001$ and $p<0.01$ ), female-synbiotic group (resp. $p<0.001$ and $p<0.001$ ), and male-synbiotic group (resp. $p<0.01$ and $p<0.05$ ) in comparison to the their control groups before experiments. Concentrations of GSSG in the synbiotic group $(p<0.05)$, female-synbiotic group $(p<0.001)$, and male-synbiotic group $(p<0.01)$ were lower versus control groups. There was a significant decrease in the GSH/GSSG ratio in the control groups $(p<0.05)$. Administration of synbiotics resulted in an increase in the GSH/GSSG ratio in the synbiotic group $(p<0.001)$, femalesynbiotic group $(p<0.001)$, and male-synbiotic group $(p<$ 0.05 ), compared with the control groups (Table 1).

The supplementation of synbiotics resulted in an increase in -SH groups in the synbiotic group $(p<0.05)$, femalesynbiotic group $(p<0.001)$, and male-synbiotic group $(p<$ 0.01 ) versus control groups (Table 1 ).

\section{Discussion}

Our results indicate that the concentration of MDA and $\mathrm{H}_{2} \mathrm{O}_{2}$ in human plasma was a higher in synbiotic " 0 " group than 
in control "0" group but there was no significant difference. This observed group variation in oxidative stress parameters could be explained by influence of various factors. Some published work has focused on influence of environmental factors, for example, seasonal variations $[24,25]$ on oxidative stress parameters. Also, when the physical exercise takes place under environmental conditions such as cold and pollution or when the intensity is high there is overproduction of $\mathrm{H}_{2} \mathrm{O}_{2}$ (autoxidation of haemoglobin) [26].

This paper shows that administration of synbiotics caused a significant decrease in the MDA and $\mathrm{H}_{2} \mathrm{O}_{2}$ concentration in the human plasma. These finding are consistent with a recent study [10]. We observed a greater reduction in the concentration of MDA and $\mathrm{H}_{2} \mathrm{O}_{2}$ in female-synbiotic group. This fact can be explained by the increased activity of antioxidant enzymes (particularly CAT) in women who took synbiotics [20]. Melatonin can regulate CAT activity. Its concentration during the day is higher in autumn and winter [27]. Moreover, its levels are higher in females with psychological stress [28] derived from lifestyle habits, living environment, or premenstrual syndrome. This observed group variation could be explained also by different levels of hormones (testosterone and oestradiol). Estrogens have in vitro and in vivo antioxidant effects [29]. These parameters were not measured at work.

However, several studies [11, 30] have shown no significant differences in MDA concentrations after the probiotics application in humans. Mazloom et al. [11] examined the effect of probiotic administration on the MDA concentration in patients with type 2 diabetes. The authors showed a decrease in MDA levels, but these results were not statistically significant. Vaghef-Mehrabany et al. [30] reported no significant differences in MDA concentrations after probiotics application. A study was carried on 46 woman with rheumatoid arthritis (RA). They received probiotic containing $L$. casei for 8 wks.

Several other studies confirm the ability of probiotics strains to decrease oxidative stress parameters, especially MDA level. Yadav et al. [31] observed that probiotic containing L. acidophilus NCDC14 and L. casei NCDC19 decreased STZ-induced oxidative damage in pancreatic tissues by inhibiting lipid peroxidation. Rajpal and Kansal [32] proved that probiotic (L. acidophilus + B. bifidum) stimulates antioxidant pathways in rats. Hathout et al. [33] evaluated the protective effect of $L$. casei or/and $L$. reuteri against aflatoxin(AFs-) induced oxidative stress in female Sprague Dawley rats. Administration of combined $L$. casei and L. reuteri in rats showed decrease in MDA concentration in these organs. Treatment with $L$. casei did not affect MDA levels; on the other hand, treatment with $L$. reuteri caused a significant decrease in MDA level in the liver but insignificant decrease in the kidney.

Other authors [34] focused on B. longum subsp. longum strains and their bioaccessible antioxidants. Mikelsaar and Zilmer [35] noted that L. fermentum ME-3 has antioxidative properties. They confirmed that this probiotic increased antioxidative activity in different types of clinical studies (double-blind, placebo-controlled, crossover) and in different subjects (healthy volunteers, allergic patients, and those recovering from stroke). The authors observed its good hydroxyl radical scavenging efficiency and ability to survive in high hydrogen peroxide environment.

Our results show that administration of synbiotic resulted in a significant increase in the GSHt, GSH, and -SH free groups content. Moreover, levels were higher in women than in men after synbiotic administration. This gender variation could be explained by different concentrations of hormones, such as oestradiol and testosterone [29]. It is reported that psychological stress reduces GSH concentrations and leads to increased oxidative stress parameters [36-38]. Stress may increase superoxide anion formation and subsequently $\mathrm{H}_{2} \mathrm{O}_{2}$ generation. Moreover, GSH deficiency can result from inadequate dietary intake of methionine or cysteine $[39,40]$. The activity of GPx was also decreased in rats exposed to stress [41]. Moreover, plasma iron and factors that could affect its levels, for example, diet, are associated with oxidative stress parameters concentration in human [42]. Some authors described that high plasma $\alpha$-tocopherol and high $\beta+\gamma$ tocopherol levels were associated with elevated plasma MDA level [43].

Several studies have shown that probiotics can enhance the activity of nonenzymatic antioxidants, for example, glutathione. Asemi et al. [44] described effects of daily consumption of multispecies probiotic supplements on oxidative stress in diabetic patients. After administration of this probiotic supplement, consisting of 7 viable and freeze-dried strains L. acidophilus, L. casei, L. rhamnosus, L. bulgaricus, B. breve, B. longum, and S. thermophilus, plasma GSHt was increased. Another study [45] confirmed that consumption of synbiotic (L. sporogenes) food by diabetic patients for 6 weeks had significant positive effects on plasma GSHt levels. Taghizadeh et al. [46] proved that consumption of synbiotic food for 9 weeks resulted in a significant rise in plasma GSH levels versus control. Similarly, another study [47] analyzed effects of probiotic (L. casei, L. acidophilus, and B. bifidum/7 wks) supplementation on biomarkers of oxidative stress in patients with major depressive disorder (MDD). An increased glutathione level was observed after probiotic supplementation compared with the placebo group.

Many authors describe correlations between probiotics and glutathione concentrations in animals.

Erginel et al. [48] evaluated antioxidant mechanisms of probiotics on gut mucosa in peritonitis. Rats were treated with probiotics after CLP-induced peritonitis/5 days or before the CLP procedure and after the surgery/5 days. The authors reported increased glutathione levels. Ogita et al. [49] obtained similar results. Tian et al. [13] observed that administration of L. rhamnosus CCFM1107 elevated the glutathione level in mice.

Verma and Shukla [50] showed that the use of synbiotics (L. rhamnosus + L. acidophilus + inulin) is a better prophylactic strategy than the use of probiotic and prebiotic alone because of a greater increase in antioxidants concentration (particularly GSH), associated with stronger attenuation of DMH-induced tumorigenesis. Kavitha et al. [51] assessed the effect of combination treatment of insulin, pioglitazone, and synbiotic on streptozotocin- (STZ-) induced diabetic rats. They observed increased GSH concentration. Lutgendorff 
et al. [52] confirmed that probiotics enhanced the biosynthesis of glutathione, which may have reduced activation of inflammation and acinar cell injury and ameliorated experimental AP, via a reduction in oxidative stress. Şengül et al. [53] assessed two probiotic strains, L. delbrueckii subsp. bulgaricus B3 and L. delbrueckii subsp. bulgaricus A13, and proved that EPS-producing probiotic bacteria significantly attenuate oxidative stress in experimental colitis.

However, some authors have noted a decrease in glutathione level after probiotic supplementation. Coşkun Cevher et al. [54] evaluated the effect of L. delbrueckii subsp. bulgaricus administration on systemic and intestinal oxidant-antioxidant events in splenectomized rats. Plasma and small intestine tissue lipid peroxidation, -SH group, and glutathione levels were determined. In this work, thiobarbituric acid reactive substances (TBARS) level was decreased by L. delbrueckii subsp. bulgaricus supplementation after or both after and before splenectomy but GSHt level was lower. Similarly, Erdogan et al. [55] proved that synbiotics and phytobiotics in combination (Enterococcus faecium, FOS) significantly increased plasma malondialdehyde (MDA) levels and decreased GSHt concentration in the blood of broilers. Recently, Bahmani et al. [56] observed that consumption of synbiotic bread for 8 weeks among patients with T2DM had beneficial effects on plasma MDA concentration but it did not affect plasma GSH level.

Recent studies support a gender-dependent difference/ signaling pathway that could be based in the intestine and/or immune system [57]. Alzamora et al. [58] described that estrogen can affect gut and immune system function. Pacifici [59] proved that probiotic (L. reuteri) impacts estrogen or/and progesterone sensitive pathways in male mice that are fully active in adult females (insensitive to the bacterium). Many authors [60-63] claim that supplementation of probiotics with or without inulin increases serum testosterone level. This effect is associated with the hypocholesterolemic action of probiotics by metabolizing cholesterol to testosterone synthesis.

Another theory says that gut microbiota composition depends on interactions between host diet and gender. In Bolnick et al. study [64] diet-microbiota associations were sex dependent in humans. Experimental diet manipulations in mice confirmed that diet affects microbiota differently in males versus females. The prevalence of genotype by environment (sex by diet) interactions implies that therapies to treat dysbiosis might have sex-specific effects.

It has been reported that gender is a crucial determinant of probiotic effects. For example, an application of the $L$. reuteri (ATCC PTA 6475) on mice has elicited genderdependent responses in TNF- $\alpha$ suppression and bone density [57]. Another study also suggested that gut-associated microorganisms with host immune system responses and metabolic activity are supported by biology distinct to the host gender [65]. Lönnermark et al. [66] described that gender, but not administration of the probiotic, may influence acute symptoms during Salmonella infection and possibly clearance of Salmonella. There was a difference in gender symptoms in the postinfectious phase, which were modified by the probiotic.
A weakness of the study is the use of only five biomarkers of oxidative stress. Measurement of more oxidative stress parameters will give a more comprehensive picture of their significance. In our work, there was a significant negative correlation between plasma glutathione and MDA levels after synbiotics administration (Pearson correlation coefficient $=$ $-0.469, p<0.001)$. However, present study had several others limitations. There was not significant trend between other OS parameters. For example, there was a positive but not significant correlation between GSH and - SH free groups content. Moreover, there were several factors which might have influence on OS parameters levels, for example, psychological stress [28] derived from lifestyle habits, living environment, or premenstrual syndrome (female). In this study we applied widely used method for oxidative stress parameters determination at different sensitivity. To measure the concentration of MDA special kit was used. The assay kit detects malondialdehyde concentration as low as $1 \mathrm{nmol} /$ well colorimetrically. MDA level is the most reliable biomarker, because it is a product of lipid oxidation. Glutathione measurement is important to assess oxidative stress parameters. Also -SH free groups content measurement may provide additional information on the redox state of a subjects. Sensitivity of the determination of total sulfhydryl groups in plasma using Ellman's reagent is $50 \mu \mathrm{M}$ to $1000 \mu \mathrm{M}$ (glutathione determination $=0.1 \mu \mathrm{M}$ ).

The work was not blinded because the control group did not consume any supplements during the experiment. The key difference between presented study and others with placebo group is that their experiment was carried out only on patients with different diseases, for example, that increasing oxidative stress.

Our results are consistent with the results of Martarelli et al. [67]. Authors proved that probiotics protect the human body from oxidative stress damage in a healthy volunteers (in not blinded study).

\section{Conclusion}

Synbiotics containing L. casei plus inulin are effective compounds that protect a human body from oxidative stress damage. Synbiotics may have a positive influence on selected oxidative stress parameters, such as MDA and glutathione concentrations.

\section{Abbreviations}

GPx: Glutathione peroxidase

GR: $\quad$ Glutathione reductase

GSH: Reduced glutathione

GSSG: Glutathione disulfide

GSHt: Total glutathione

LAB: $\quad$ Lactic acid bacteria

MDA: Malondialdehyde

NADPH: Nicotinamide adenine dinucleotide phosphate

ROS: Reactive oxygen species

SOD: $\quad$ Superoxide dismutase. 


\section{Competing Interests}

The authors declare no conflict of interests.

\section{Acknowledgments}

This study was supported by Grant 503/0-149-03/503-01-005 from the Medical University of Lodz.

\section{References}

[1] P. D. Ray, B.-W. Huang, and Y. Tsuji, "Reactive oxygen species (ROS) homeostasis and redox regulation in cellular signaling," Cellular Signalling, vol. 24, no. 5, pp. 981-990, 2012.

[2] P. Song and M. H. Zou, "Roles of reactive oxygen species in physiology and pathology," in Atherosclerosis: Risks, Mechanisms, and Therapies, pp. 379-392, John Wiley \& Sons, 2015.

[3] T. F. Brewer, F. J. Garcia, C. S. Onak, K. S. Carroll, and C. J. Chang, "Chemical approaches to discovery and study of sources and targets of hydrogen peroxide redox signaling through NADPH oxidase proteins," Annual Review of Biochemistry, vol. 84, pp. 765-790, 2015.

[4] G. R. Buettner, "Superoxide dismutase in redox biology: the roles of superoxide and hydrogen peroxide," Anti-Cancer Agents in Medicinal Chemistry, vol. 11, no. 4, pp. 341-346, 2011.

[5] A. Ayala, M. F. Muñoz, and S. Argüelles, "Lipid peroxidation: production, metabolism, and signaling mechanisms of malondialdehyde and 4-hydroxy-2-nonenal," Oxidative Medicine and Cellular Longevity, vol. 2014, Article ID 360438, 31 pages, 2014.

[6] Y. Dotan, D. Lichtenberg, and I. Pinchuk, "Lipid peroxidation cannot be used as a universal criterion of oxidative stress," Progress in Lipid Research, vol. 43, no. 3, pp. 200-227, 2004.

[7] V. I. Lushchak, "Glutathione homeostasis and functions: potential targets for medical interventions," Journal of Amino Acids, vol. 2012, Article ID 736837, 26 pages, 2012.

[8] D. M. Townsend, K. D. Tew, and H. Tapiero, "The importance of glutathione in human disease," Biomedicine and Pharmacotherapy, vol. 57, no. 3, pp. 145-155, 2003.

[9] G. R. Gibson and M. B. Roberfroid, "Dietary modulation of the human colonic microbiota: introducing the concept of prebiotics," Journal of Nutrition, vol. 125, no. 6, pp. 1401-1412, 1995.

[10] H. S. Ejtahed, J. Mohtadi-Nia, A. Homayouni-Rad, M. Niafar, M. Asghari-Jafarabadi, and V. Mofid, "Probiotic yogurt improves antioxidant status in type 2 diabetic patients," Nutrition, vol. 28, no. 5, pp. 539-543, 2012.

[11] Z. Mazloom, A. Yousefinejad, and M. H. Dabbaghmanesh, "Effect of probiotics on lipid profile, glycemic control, insulin action, oxidative stress, and inflammatory markers in patients with type 2 diabetes: a clinical trial," Iranian Journal of Medical Sciences, vol. 38, no. 1, pp. 38-43, 2013.

[12] H. Suo, X. Zhao, Y. Qian et al., "Lactobacillus fermentum Suo attenuates $\mathrm{HCl}$ /ethanol induced gastric injury in mice through its antioxidant effects," Nutrients, vol. 8, no. 3, article 155, 2016.

[13] F. Tian, F. Chi, G. Wang et al., "Lactobacillus rhamnosus CCFM1107 treatment ameliorates alcohol-induced liver injury in a mouse model of chronic alcohol feeding," Journal of Microbiology, vol. 53, no. 12, pp. 856-863, 2015.

[14] Y. Zhang, L. Wang, J. Zhang et al., "Probiotic Lactobacillus casei Zhang ameliorates high-fructose-induced impaired glucose tolerance in hyperinsulinemia rats," European Journal of Nutrition, vol. 53, no. 1, pp. 221-232, 2014.
[15] Q. Zhai, G. Wang, J. Zhao et al., "Protective effects of lactobacillus plantarum ccfm 8610 against acute cadmium toxicity in mice," Applied and Environmental Microbiology, vol. 79, no. 5, pp. 1508-1515, 2013.

[16] M. A. Uskova and L. V. Kravchenko, "Antioxidant properties of lactic acid bacteria-probiotic and yogurt strains," Voprosy Pitaniia, vol. 78, no. 2, pp. 18-23, 2009.

[17] S. H. Al-Sheraji, A. Ismail, M. Y. Manap, S. Mustafa, R. M. Yusof, and F. A. Hassan, "Hypocholesterolaemic effect of yoghurt containing Bifidobacterium pseudocatenulatum $\mathrm{G} 4$ or Bifidobacterium longum BB536," Food Chemistry, vol. 135, no. 2, pp. 356-361, 2012.

[18] D. Gao, Z. Gao, and G. Zhu, "Antioxidant effects of Lactobacillus plantarum via activation of transcription factor Nrf2," Food \& Function, vol. 4, no. 6, pp. 982-989, 2013.

[19] A. N. Wang, X. W. Yi, H. F. Yu, B. Dong, and S. Y. Qiao, "Free radical scavenging activity of Lactobacillus fermentum in vitro and its antioxidative effect on growing-finishing pigs," Journal of Applied Microbiology, vol. 107, no. 4, pp. 1140-1148, 2009.

[20] P. Kleniewska, A. Hoffmann, E. Pniewska, and R. Pawliczak, "The influence of probiotic Lactobacillus casei in combination with prebiotic inulin on the antioxidant capacity of human plasma," Oxidative Medicine and Cellular Longevity, vol. 2016, Article ID 1340903, 10 pages, 2016.

[21] Y.-F. Qiao, W.-J. Guo, L. Li et al., "Melatonin attenuates hypertension-induced renal injury partially through inhibiting oxidative stress in rats," Molecular Medicine Reports, vol. 13, no. 1, pp. 21-26, 2016.

[22] C. S. L. Vicente, Y. Ikuyo, R. Shinya, M. Mota, and K. Hasegawa, "Catalases induction in high virulence pinewood nematode Bursaphelenchus xylophilus under hydrogen peroxide-induced stress," PLoS ONE, vol. 10, no. 4, Article ID e0123839, 2015.

[23] G. L. Ellman, "SH groups determination in biological fluids," Analytical Biochemistry, vol. 46, pp. 233-235, 1970.

[24] T. Balog, S. Sobočanec, V. Šverko et al., "The influence of season on oxidant-antioxidant status in trained and sedentary subjects," Life Sciences, vol. 78, no. 13, pp. 1441-1447, 2006.

[25] J. Kodydková, L. Vávrová, M. Kocík, and A. Žák, "Human catalase, its polymorphisms, regulation and changes of its activity in different diseases," Folia Biologica, vol. 60, no. 4, pp. 153-167, 2014.

[26] A. Rahal, A. Kumar, V. Singh et al., "Oxidative stress, prooxidants, and antioxidants: the interplay," BioMed Research International, vol. 2014, Article ID 761264, 19 pages, 2014.

[27] L. Rönnberg, A. Kauppila, J. Leppäluoto, H. Martikainen, and O. Vakkuri, "Circadian and seasonal variation in human preovulatory follicular fluid melatonin concentration," Journal of Clinical Endocrinology and Metabolism, vol. 71, no. 2, pp. 492496, 1990.

[28] Y. Ito, T. Iida, Y. Yamamura et al., "Relationships between salivary melatonin levels, quality of sleep, and stress in young japanese females," International Journal of Tryptophan Research, vol. 6, no. 1, pp. 75-85, 2013.

[29] J. Schröder, M. Dören, B. Schneider, and M. Oettel, "Are the antioxidative effects of $17 \beta$-estradiol modified by concomitant administration of a progestin?" Maturitas, vol. 25, no. 2, pp. 133139, 1996.

[30] E. Vaghef-Mehrabany, A. Homayouni-Rad, B. Alipour, S.-K. Sharif, L. Vaghef-Mehrabany, and S. Alipour-Ajiry, "Effects of probiotic supplementation on oxidative stress indices in women with rheumatoid arthritis: a randomized double-blind clinical 
trial," Journal of the American College of Nutrition, vol. 35, no. 4, pp. 291-299, 2016.

[31] H. Yadav, S. Jain, and P. R. Sinha, "Oral administration of dahi containing probiotic Lactobacillus acidophilus and Lactobacillus casei delayed the progression of streptozotocin-induced diabetes in rats," Journal of Dairy Research, vol. 75, no. 2, pp. 189195, 2008.

[32] S. Rajpal and V. K. Kansal, "Probiotic Dahi containing Lactobacillus acidophilus and Bifidobacterium bifidum stimulates antioxidant enzyme pathways in rats," Milchwissenschaft, vol. 64, no. 3, pp. 287-290, 2009.

[33] A. S. Hathout, S. R. Mohamed, A. A. El-Nekeety, N. S. Hassan, S. E. Aly, and M. A. Abdel-Wahhab, "Ability of Lactobacillus casei and Lactobacillus reuteri to protect against oxidative stress in rats fed aflatoxins-contaminated diet," Toxicon, vol. 58, no. 2, pp. 179-186, 2011.

[34] M. Gagnon, P. Savard, A. Rivière, G. Lapointe, and D. Roy, "Bioaccessible antioxidants in milk fermented by Bifidobacterium longum subsp. longum strains," BioMed Research International, vol. 2015, Article ID 169381, 12 pages, 2015.

[35] M. Mikelsaar and M. Zilmer, "Lactobacillus fermentum ME-3an antimicrobial and antioxidative probiotic," Microbial Ecology in Health and Disease, vol. 21, no. 1, pp. 1-27, 2009.

[36] I. Cernak, V. Savic, J. Kotur et al., "Alterations in magnesium and oxidative status during chronic emotional stress," Magnesium Research, vol. 13, no. 1, pp. 29-36, 2000.

[37] M. Sivoňová, I. Žitňanová, L. Hlinčíková, I. Škodáček, J. Trebatická, and Z. Ďuračková, "Oxidative stress in university students during examinations,” Stress, vol. 7, no. 3, pp. 183-188, 2004.

[38] E. Şahin and S. Gümüşlü, "Stress-dependent induction of protein oxidation, lipid peroxidation and anti-oxidants in peripheral tissues of rats: comparison of three stress models (immobilization, cold and immobilization-cold)," Clinical and Experimental Pharmacology and Physiology, vol. 34, no. 5-6, pp. 425-431, 2007.

[39] S. K. Biswas and I. Rahman, "Environmental toxicity, redox signaling and lung inflammation: the role of glutathione," Molecular Aspects of Medicine, vol. 30, no. 1-2, pp. 60-76, 2009.

[40] P. Ghezzi, "Role of glutathione in immunity and inflammation in the lung," International Journal of General Medicine, vol. 4, pp. 105-113, 2011.

[41] D. Akpinar, P. Yargiçoğlu, N. Derin, Y. Alicigüzel, and A. Ağar, "The effect of lipoic acid on antioxidant status and lipid peroxidation in rats exposed to chronic restraint stress," Physiological Research, vol. 57, no. 6, pp. 893-901, 2008.

[42] C. Lasheras, S. González, J. M. Huerta, S. Braga, A. M. Patterson, and S. Fernández, "Plasma iron is associated with lipid peroxidation in an elderly population," Journal of Trace Elements in Medicine and Biology, vol. 17, no. 3, pp. 171-176, 2003.

[43] R. V. Cooney, G. Maskarinec, A. A. Franke et al., "Association of tocopherols with circulating autoantibody levels against an oxidized DNA nucleoside in humans," Free Radical Biology and Medicine, vol. 31, no. 4, pp. 460-468, 2001.

[44] Z. Asemi, Z. Zare, H. Shakeri, S.-S. Sabihi, and A. Esmaillzadeh, "Effect of multispecies probiotic supplements on metabolic profiles, hs-CRP, and oxidative stress in patients with type 2 diabetes," Annals of Nutrition and Metabolism, vol. 63, no. 1-2, pp. 1-9, 2013.

[45] Z. Asemi, A. Khorrami-Rad, S.-A. Alizadeh, H. Shakeri, and A. Esmaillzadeh, "Effects of synbiotic food consumption on metabolic status of diabetic patients: a double-blind randomized cross-over controlled clinical trial," Clinical Nutrition, vol. 33, no. 2, pp. 198-203, 2014.

[46] M. Taghizadeh, T. Hashemi, H. Shakeri et al., "Synbiotic food consumption reduces levels of triacylglycerols and VLDL, but not cholesterol, LDL, or HDL in plasma from pregnant women," Lipids, vol. 49, no. 2, pp. 155-161, 2014.

[47] G. Akkasheh, Z. Kashani-Poor, M. Tajabadi-Ebrahimi et al., "Clinical and metabolic response to probiotic administration in patients with major depressive disorder: a randomized, doubleblind, placebo-controlled trial," Nutrition, vol. 32, no. 3, pp. 315320, 2016.

[48] B. Erginel, F. A. Aydin, T. Erginel et al., "Antioxidant effects of probiotics in experimentally induced peritonitis," Surgical Infections, vol. 17, no. 1, pp. 114-118, 2016.

[49] T. Ogita, P. Bergamo, F. Maurano et al., "Modulatory activity of Lactobacillus rhamnosus OLL2838 in a mouse model of intestinal immunopathology," Immunobiology, vol. 220, no. 6, pp. 701-710, 2015.

[50] A. Verma and G. Shukla, "Synbiotic (Lactobacillus rhamnosus +Lactobacillus acidophilus+inulin) attenuates oxidative stress and colonic damage in 1,2 dimethylhydrazine dihydrochloride-induced colon carcinogenesis in Sprague-Dawley rats: a long-term study," European Journal of Cancer Prevention, vol. 23, no. 6, pp. 550-559, 2014.

[51] K. Kavitha, A. G. Reddy, K. K. Reddy, C. S. V. S. Kumar, G. Boobalan, and K. Jayakanth, "Hypoglycemic, hypolipidemic and antioxidant effects of pioglitazone, insulin and synbiotic in diabetic rats," Veterinary World, vol. 9, no. 2, pp. 118-122, 2016.

[52] F. Lutgendorff, L. M. Trulsson, L. P. Van Minnen et al., "Probiotics enhance pancreatic glutathione biosynthesis and reduce oxidative stress in experimental acute pancreatitis," American Journal of Physiology-Gastrointestinal and Liver Physiology, vol. 295, no. 5, pp. G1111-G1121, 2008.

[53] N. Şengül, S. Işık, B. Aslım, G. Uçar, and A. E. Demirbağ, "The effect of exopolysaccharide-producing probiotic strains on gut oxidative damage in experimental colitis," Digestive Diseases and Sciences, vol. 56, no. 3, pp. 707-714, 2011.

[54] Ş. Coşkun Cevher, B. Balabanli, and B. Aslim, "Effects of probiotic supplementation on systemic and intestinal oxidantantioxidant events in splenectomized rats," Surgery Today, vol. 45, no. 9, pp. 1166-1172, 2014.

[55] Z. Erdoĝan, S. Erdoĝan, Ö. Aslantaş, and S. Çelik, "Effects of dietary supplementation of synbiotics and phytobiotics on performance, caecal coliform population and some oxidant/antioxidant parameters of broilers," Journal of Animal Physiology and Animal Nutrition, vol. 94, no. 5, pp. e40-e48, 2010.

[56] F. Bahmani, M. Tajadadi-Ebrahimi, F. Kolahdooz et al., "The consumption of synbiotic bread containing lactobacillus sporogenes and inulin affects nitric oxide and malondialdehyde in patients with Type 2 diabetes mellitus: randomized, doubleblind, placebo-controlled trial," Journal of the American College of Nutrition, vol. 35, no. 6, pp. 506-513, 2016.

[57] L. R. Mccabe, R. Irwin, L. Schaefer, and R. A. Britton, "Probiotic use decreases intestinal inflammation and increases bone density in healthy male but not female mice," Journal of Cellular Physiology, vol. 228, no. 8, pp. 1793-1798, 2013.

[58] R. Alzamora, F. O’Mahony, and B. J. Harvey, "Estrogen inhibits chloride secretion caused by cholera and Escherichia coli enterotoxins in female rat distal colon," Steroids, vol. 76, no. 9, pp. 867876, 2011. 
[59] R. Pacifici, "The immune system and bone," Archives of Biochemistry and Biophysics, vol. 503, no. 1, pp. 41-53, 2010.

[60] M. A. E. Ghoneim and S. S. Moselhy, "Impact of probioticsupplemented diet on the expression level of lactate dehydrogenase in the leukocytes of rabbits," Toxicology and Industrial Health, vol. 30, no. 3, pp. 225-232, 2014.

[61] D. C. Cavallini, R. Bedani, L. Q. Bomdespacho, R. C. Vendramini, and E. A. Rossi, "Effects of probiotic bacteria, isoflavones and simvastatin on lipid profile and atherosclerosis in cholesterol-fed rabbits: a randomized double-blind study," Lipids in Health and Disease, vol. 8, article 1, 2009.

[62] H.-S. Lye, C.-Y. Kuan, J.-A. Ewe, W.-Y. Fung, and M.-T. Liong, "The improvement of hypertension by probiotics: effects on cholesterol, diabetes, renin, and phytoestrogens," International Journal of Molecular Sciences, vol. 10, no. 9, pp. 3755-3775, 2009.

[63] L.-G. Ooi and M.-T. Liong, "Cholesterol-lowering effects of probiotics and prebiotics: a review of in vivo and in vitro Findings," International Journal of Molecular Sciences, vol. 11, no. 6, pp. 2499-2522, 2010.

[64] D. I. Bolnick, L. K. Snowberg, P. E. Hirsch et al., "Individual diet has sex-dependent effects on vertebrate gut microbiota," Nature Communications, vol. 5, article 4500, 2014.

[65] E. Karunasena, K. W. McMahon, D. Chang, and M. M. Brashears, "Host responses to the pathogen Mycobacterium avium subsp. Paratuberculosis and beneficial microbes exhibit host sex specificity," Applied and Environmental Microbiology, vol. 80, no. 15, pp. 4481-4490, 2014.

[66] E. Lönnermark, G. Lappas, V. Friman, A. E. Wold, E. Backhaus, and I. Adlerberth, "Effects of probiotic intake and gender on nontyphoid salmonella infection," Journal of Clinical Gastroenterology, vol. 49, no. 2, pp. 116-123, 2015.

[67] D. Martarelli, M. C. Verdenelli, S. Scuri et al., "Effect of a probiotic intake on oxidant and antioxidant parameters in plasma of athletes during intense exercise training," Current Microbiology, vol. 62, no. 6, pp. 1689-1696, 2011. 


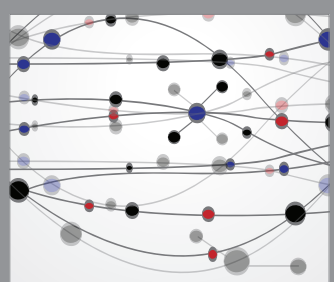

The Scientific World Journal
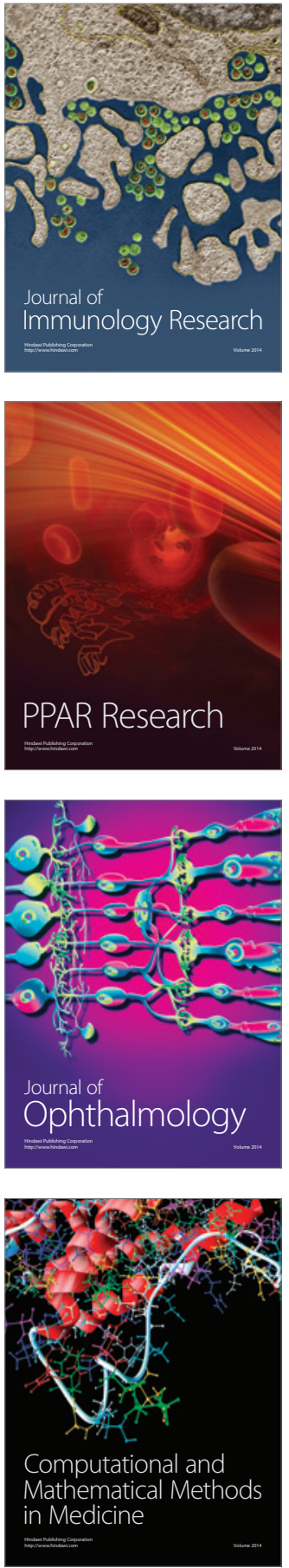

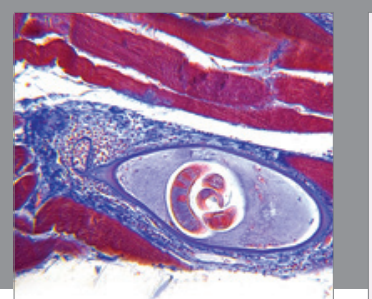

Gastroenterology Research and Practice
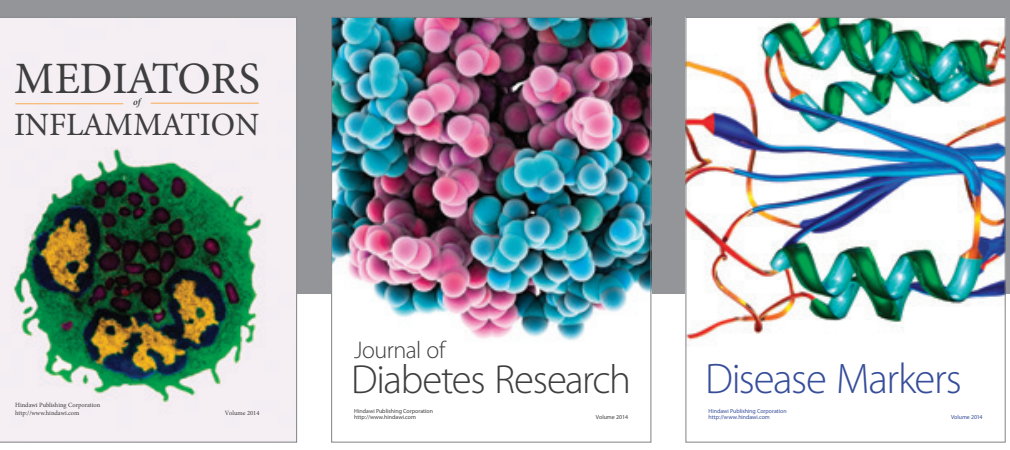

Disease Markers

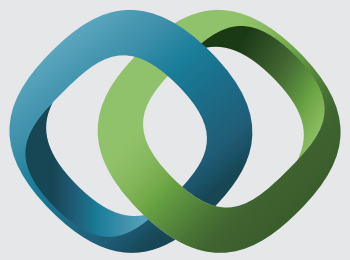

\section{Hindawi}

Submit your manuscripts at

https://www.hindawi.com
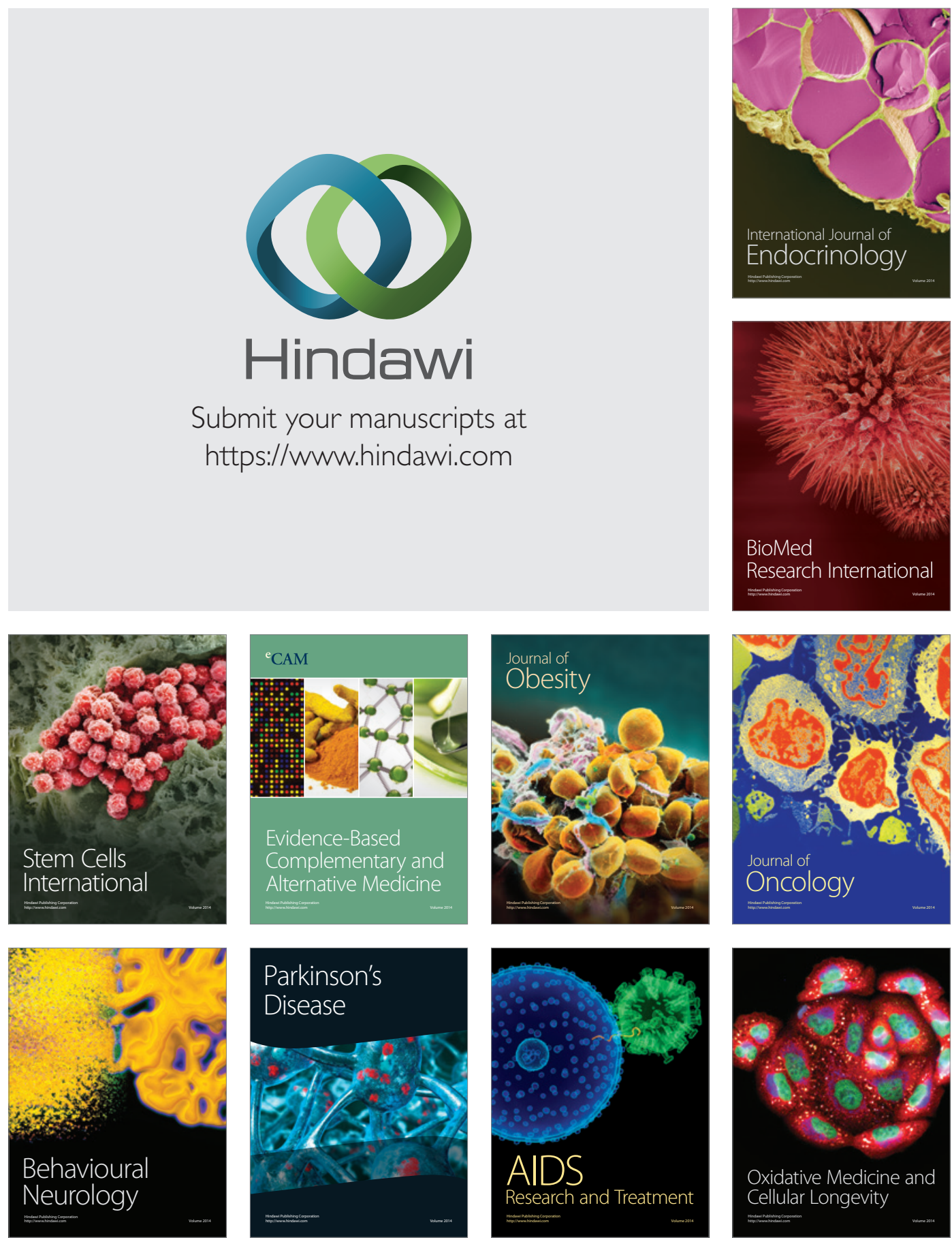